\title{
False Confessions in the Lab: A Review
}

\author{
Eric Rassin \& Han Israëls*
}

\begin{abstract}
Intuitively, confession is a strong piece of evidence, because it appears unlikely that a suspect would confess to a crime he did not commit, thereby acting against his own best interest. Surprisingly, experimental studies show that innocent and well-educated individuals do tend to confess falsely when questioned about something they did not in fact do. In this contribution, an overview is presented of the experimental research on confession evidence. Limitations and implications of the scientific insights are discussed.
\end{abstract}

Keywords: confession, interrogation, evidence

\section{Introduction}

A confession is a very strong piece of evidence in criminal proceedings, if not, in the words of Kassin, 'the prosecutor's most potent weapon'. ${ }^{1}$ This is arguably so, because if the suspect himself confesses, it is intuitively likely that he is indeed guilty. Note that the suspect has good reason not to confess. The positive appreciation of confession evidence implies that false confessions are scarce or even non-existent. In the words of Inbau et al.: 'It is our contention, however, that an innocent suspect operating within normal limits of competency would not accept physical responsibility for an act he knows he did not commit.'

Notwithstanding this common sense notion, from time to time, false confessions do occur and contribute to major miscarriages of justice. ${ }^{3}$ Infamous examples are the Birmingham six, the Guilford four, and in the United States, Henry Lee Lucas. ${ }^{4}$ The question then is whether these false confessions can be discarded as incidents. Experimental research suggests that they cannot. The aim of the present contribution is to present an

* $\quad$ Eric Rassin is Endowed Professor of Legal Psychology at the Faculty of Social Sciences and the School of Law at Erasmus University Rotterdam. Han Israëls is Assistant Professor in Legal Psychology at the Maastricht University. Please address correspondence to Eric Rassin, Faculty of Social Sciences (Institute of Psychology), Erasmus University Rotterdam, P.O. Box 1738, 3000 DR Rotterdam, The Netherlands. Email: rassin@fsw.eur.nl.

1. S.M. Kassin, 'The Psychology of Confession Evidence', 52 American Psychologist 221, at 221 (1997).

2. F.E. Inbau, J.E. Reid, J.P. Buckley \& B.C. Jayne, Criminal Interrogation and Confessions (2001), at 286.

3. M.J. Saks and J.J. Koehler, 'The Coming Paradigm Shift in Forensic Identification Science', 309 Science 892 (2005).

4. G.H. Gudjonsson, The Psychology of Interrogations and Confessions: A Handbook (2003). overview of the experimental research on confession evidence. Limitations and implications of this body of research will be tapped.

\section{Experimental Paradigm for False Confessions}

The effect of others on individuals' behaviour has been well-documented for several decades. For example, people have been found to have a strong tendency to conform to group norms, even at the cost of setting aside personal convictions. ${ }^{5}$ People also seem to be highly sensitive to authority. In his seminal study, Milgram found that the majority of participants were willing to apply dangerous electrical shocks to fellow participants, if instructed to do so by the experiment leader. ${ }^{6}$ Our recollection can also be influenced by social interaction. For example, participants remembered a videotaped car crash to be more severe if the question contained the word 'smash', compared to the employment of words like 'contact' and 'hit'. ${ }^{7}$ Leading questions can also make us believe that we saw videos which we did in fact not see. $^{8}$

The examples of the effect of social influences of individual behaviour discussed above are remote from false confessions in that they do not imply that the individual acts against his own best interest, while that is a crucial feature of a false confession. Notably, contemporary legislation and ethical guidelines make it difficult to make participants in scientific research (temporarily) act against their best interest. For example, it is ethically impossible to falsely accuse a participant of having committed murder and to incarcerate him for multiple days. To gain some insight into the extent to which people are susceptible to falsely confessing, Gudjonsson et al. asked 24,627 young adults whether they had ever been questioned by the police: 2,726 of them answered this

5. S.E. Asch, 'Opinions and Social Pressure', 193 Scientific American 31 (1955).

6. S. Milgram, 'Behavioral Study of Obedience', 67 Journal of Abnormal and Social Psychology 371 (1963). J.M. Burger, 'Replicating Milgram: Would People Still Obey Today?', 64 American Psychologist 1 (2009).

7. E.F. Loftus and J.C. Palmer, 'Reconstruction of Automobile Destruction: An Example of the Interaction between Language and Memory', 13 Journal of Verbal Learning and Verbal Behavior 585 (1974).

8. H.F.M. Crombag, W.A. Wagenaar \& P.J. van Koppen, 'Crashing Memories and the Problem of 'source Monitoring', 10 Applied Cognitive Psychology 95 (1996). M. Jelicic, T. Smeets, M.J.V. Peters, I. Candel, R. Horselenberg \& H. Merckelbach, 'Assassination of a Controversial Politician: Remembering Details from Another Non-existent Film', 20 Applied Cognitive Psychology 591 (2006). 
question affirmatively and 375 reported having given a false confession (i.e. $13.8 \%$ ). ${ }^{9}$ These findings are impressive in various ways, for example in that they pertain to real-life interrogations, and the number of respondents (recruited across Europe) is considerable. However, the findings are also limited, for example in that they are silent about the number of true confessions, and in scientific terms, it must be admitted that they are not the fruit of experimental research.

In the past twenty years, researchers have succeeded in developing experimental paradigms that yield findings that try to model the effects of real interrogations. First, Kassin and Kiechel invited seventy-nine undergraduates to participate in a reaction time computer task. ${ }^{10}$ Participants were explicitly prohibited to press the alt-key, because that would cause the computer to crash and all data to be lost. A few minutes after the experiment had commenced, the computer screen turned blank, and the experiment leader entered the room accusing the participant of having pressed the altkey. In fact, alt-key presses were registered, and none of the participants had actually pressed it. The question was how many participants were willing to sign a written confession of having pressed the alt-key. Before looking at the results, it is important to acknowledge two crucial variables. First, some participants had worked under low time pressure (i.e. 43 stimuli per minute), whereas others had worked under high pressure (i.e. 67 stimuli). Second, in some cases, a fellowparticipant testified that (s)he had witnessed that the participant had pressed the alt-key. Again, this fellowparticipant was in fact a co-worker of the experiment leader. Hence in these cases, there was false incriminating evidence. The percentage of participants signing the confession as a function of time pressure and additional incriminating witness evidence is displayed in Table 1. As can be seen in the first row (compliance) an astonishing high percentage of participants did sign the confession. Further, time pressure and false witness testimony increased confession rates.

Kassin and Kiechel also tried to explore what reasons participants had to sign the confession. To gain some insight therein, a second confederate who supposedly was waiting for his turn to participate outside of the laboratory asked the participant what had happened during the experiment. Based on this conversation, it could be assessed whether the participant had confessed against better judgment (i.e. compliance; e.g. 'they accused me of pressing the alt-key, but I didn't, I confessed anyway'), or whether (s)he had actually started to believe in his guilt (i.e. internalisation; e.g. 'I must have pressed the alt-key'), or even confabulated details explaining

9. G.H. Gudjonsson, J.F. Sigurdsson \& I.D. Sigfusdottir, 'Interrogation and False Confessions among Adolescents in Seven European Countries: What Background and Psychological Variables Best Discriminate between False Confessors and Non-false Confessors?', 15 Psychology, Crime \& Law 711 (2009).

10. S.M. Kassin and K.L Kiechel, 'The Social Psychology of False Confessions: Compliance, Internalization, and Confabulation', 7 Psychological Science 125 (1996). why (s)he pressed the alt-key (i.e. confabulation; e.g. 'I went out late yesterday, and that is why my head was not very clear, and I hit the alt-key'). As can be seen, a substantial proportion of the confessing participants indeed believed that they were guilty.

This final part of the study taps on an important theoretical aspect of false confession. That is, apart from voluntary, non-coerced false confessions (e.g. to become [in]famous, or to protect the actual perpetrator), two types of coerced false confessions are generally distinguished. First, in case of a coerced compliant confession, the suspect confesses, while knowing that the confession is false. A reason to do so may be the belief that confessing will stop the interrogation and/or will lead to reduction of penalty. Second, in case of a coerced internalised confession, the suspect is brought to believe that he actually did commit the pertinent crime. Different psychological processes are thought to underlie these two types of confessions. A coerced compliant confession is based on the tendency to comply, to avoid conflict, and to please one's conversational partner. By contrast, a coerced internalised confession occurs if the suspect suffers from inferior memory and/or increased suggestibility. ${ }^{11}$

Approximately ten years after the study by Kassin and Kiechel, Russano et al. developed a new paradigm to study false confessions. ${ }^{12}$ In this case, undergraduates $(N=196)$ completed several pen and paper tasks in duos (one actual participant and the other member of the pair was a confederate). For some tasks, it was explicitly forbidden to work together. In the 'guilty' condition, the confederate asked the participant for help on one of the assignments that were to be completed individually. Most of the participants acted friendly, helped the confederate, but thereby broke the rules. In the 'innocent' condition, all individual tasks were indeed completed individually. At the end of the test, the experiment leader informed the duo that he had noticed something strange: in one of the individual tasks, both members of the pair had given the same wrong answer. Hence, the suspicion of cheating arose. Participants were taken apart and questioned about this. With this design, participants in the guilty condition may confess truly (note that true confessions did not occur in the study by Kassin \& Kiechel), and those in the innocent condition may confess falsely.

Russano et al. tested four interrogation protocols: (i) a protocol in which the participant was merely accused of having worked together, without further tactics, (ii) a protocol in which a deal was offered to the participant ('things could probably be settled quickly if you sign the confession'), (iii) one in which crime severity was minimised ('I am sure you just wanted to help, and didn't realise what a big deal it was'), and (iv) one in which the deal and minimisation were combined.

11. Gudjonsson et al. (2009), above n. 9

12. M.B. Russano, C.A. Meissner, F.M. Narchet \& S.M. Kassin, 'Investigating True and False Confessions within a Novel Experimental Paradigm', 16 Psychological Science 481 (2005). 
Table 2 presents the percentages of confessing participants (true and false) as a function of interrogation protocol. As can be seen, the number of true confessions increases with the employment of subtle tactics, but so (and even more so) does the number of false confessions. Consequently, the diagnostic value, which is simply the percentage of true confessions divided by the percentage of false ones, decreases. Note that if the diagnostic value reaches one, a confession no longer discriminates between guilty and innocent suspects. Ideally, the diagnostic value of the evidence as a whole has been argued to be at least $24 .{ }^{13}$ Hence, the data neatly illustrate that a confession does not suffice to conclude that the suspect is guilty.

\section{Summary of Experiments on False Confessions}

Since the introduction of the two paradigms described in the previous paragraph, the original studies by Kassin and Kiechel in 1996 and Russano et al. in 2005 have been replicated several times. To gain overview of this literature, search engine Scopus was consulted in March-April 2013 following two strategies. First, the term 'false confession' was entered, resulting in 225 hits. Second, 123 articles citing the original Kassin and Kiechel study were searched. Title and abstract of all publications were scanned to determine whether the article described an experiment on false confessions. The result of this literature search is presented in Table 3. Sixteen articles were obtained, describing twenty-one experiments. The mean weighted false confession rate was $45 \%$ (range: $4 \%$ to $100 \%$ ).

True confession rates and the diagnostic value of confessions can only be calculated from studies employing the Russano et al. paradigm, because those experiments include false and true confessions. Based on those studies, the mean true confession rate turned out to be $74 \%$. The diagnostic value of a confession is (74\% divided by 24\% [331 innocent participants of whom 78 confessed]) 3.1. The literature sheds some preliminary light on the causes of false confessions. Or given the large percentage of false confessions, it may be better to simply take human susceptibility to social context as the primary cause of false confession and to merely search for factors that aggravate or limit the tendency to falsely confess. First, as borne out by the data of Kassin and Kiechel several situational factors are relevant. Both cognitive load (i.e. time pressure) and false incriminating witness statements increased false confession rate. As known from the study by Russano et al., minimising crime severity and offering lenience also promote the occurrence of false confessions. Plausibility of the accusation may also influence the likelihood of admission. ${ }^{14}$ Finally, the interrogator's eagerness to elicit a confession may also increase the likelihood of a false confession. ${ }^{15}$ Second, in theory, several personality characteristics can be expected to promote the tendency to falsely confess. Compliance should be associated with confessing in an experimental set-up. However, the findings are not encouraging, or mixed to say the least. ${ }^{16}$ Similar ambiguity can be seen when exploring the relation between suggestibility and false confessions: in some studies such a relation is observed, ${ }^{17}$ in others it is not. ${ }^{18} \mathrm{By}$ and large, evidence for a relation between theoretically meaningful personality characteristics and false confessions is meagre.

\section{Discussion}

The data summarised in Table 3 suggest that normal individuals (i.e. non-clinical and non-selected participants) are quite susceptible to falsely confess when questioned about a crime. Evidently, there are some limitations to the scientific data. First, the consequences of a false confession in the experiments discussed are substantially inferior to those in real police investigations. Researchers have employed small financial punishments, working as a lab-assistant, and threats of disciplinary measures as negative consequences. Such consequences are not comparable to long prison sentences. However, the social pressure to which students are exposed in the experiments is analogously inferior to that to which suspects in police interrogations are subjected. In fact, it can well be argued that the pressure-consequences ratio of real police interrogations and scientific experiments are comparable, after all. Nonetheless, the extrapolation from laboratory studies as described in the present contribution to real-life situations remains problematic.

Second, it must be stressed that the scientific data do not imply that $45 \%$ of all confessions are false. This is so, because the base rate of innocent suspects in police investigations is unknown. To illustrate, researcher

14. J.R. Klaver, Z. Lee \& V.G. Rose, 'Effects of Personality, Interrogation Techniques and Plausibility in an Experimental False Confession Paradigm', 13 Legal and Criminological Psychology 71 (2008).

15. F.M. Narchet, C.A. Meissner \& M.B. Russano, 'Modeling the Influence of Investigator Bias on the Elicitation of True and False Confessions', 35 Law and Human Behavior 452 (2011).

16. J.P. Blair, 'The Roles of Interrogation, Perception, and Individual Differences in Producing Compliant False Confessions', 13 Psychology, Crime \& Law 173 (2007). R. Horselenberg, H. Merckelbach \& S. Josephs, 'Individual Differences and False Confessions: A Conceptual Replication of Kassin and Kiechel (1996)', 9 Psychology, Crime and Law 1 (2003).

17. Klaver et al. (2008), above n. 14. A.D. Redlich and G.S. Goodman, 'Taking Responsibility for an Act Not Committed: The Influence of Age and Suggestibility', 27 Law and Human Behavior 141 (2003).

18. I. Candel, H. Merckelbach, S. Loyen \& H. Reyskens, "“I Hit the Shift-key and Then the Computer crashed": Children and False Admissions', 38 Personality and Individual Differences 1381 (2005). Horselenberg et al. (2003), above n. 16. K.D. Forrest, T.A., Wadkins \& R.L. Miller, 'The Role of Preexisting Stress on False Confessions: An Empirical Study', 3 Journal of Credibility Assessment and Witness Psychology 23 (2002). 


\begin{tabular}{lllll}
\hline & \multicolumn{2}{c}{ No witness } & \multicolumn{2}{c}{ Witness } \\
\hline & Low pace (43) & High pace (67) & Low pace & High pace \\
\hline Compliance & 35 & 65 & 89 & 100 \\
\hline Internalisation & 0 & 12 & 44 & 65 \\
\hline Confabulation & 0 & 0 & 6 & 35
\end{tabular}

Kassin once asked a police interrogator whether he feared the occurrence of false confessions. The officer replied: 'No, because I do not interrogate innocent people. ${ }^{19}$ If this were so, the scientific data on false confessions would not be alarming: $45 \%$ of zero innocent suspects is still zero. Imagine that only $10 \%$ of all interrogated suspects were innocent and $90 \%$ were guilty. According to data in Table 3, 45\% of the innocents confess and $74 \%$ of the guilty ones do. Thus, if 100 suspects (of which 10 are innocent) are interrogated, this will yield 71 confessions (of which 67 true and 4 false). Hence, given a $90-10$ base rate of guilty and innocent suspects, $5.6 \%$ of the obtained confessions will be false. The assumption that the base rate of innocent suspects is less than $50 \%$ may make the current findings correspond with some figures on miscarriages of justice, which are about $2 \%{ }^{20}$

Finally, it is important to realise that suspects are incarcerated and are thus isolated from the outside world. This may lead them to not perceive confessing during an interrogation as acting against their own best interest. Confession may well be considered the only fast and easy way out of the unpleasant situation in which the suspect finds himself. Recently, police in various Western countries have started to videotape interrogations and/or to allow counsellors to be present. These measures are meant to reduce police misconduct, to increase transparency (including the possibility to evaluate the interrogation in hindsight), and to decrease the risk of false confessions. However, the interventions may not always reach their goal. For example, Kassin alerted his audience to the possibility of framing bias (i.e. using ambiguous fragments of a videotaped interrogation in a way that suits the prosecutor or the defence) and point-of-view-bias (i.e. videotaping the interrogation from an angle that makes it impossible to see the interrogators). ${ }^{21}$ Notwithstanding, Kassin et al. recently found that the announced videotaping of interrogation, indeed, has beneficial effects such as a decrease in the tendency to employ trickery. ${ }^{22}$ As to the presence of a counsellor, it must be acknowledged that this is in some cases indeed nothing more than being present. One of us recently saw an interrogation in which a lawyer was present. The interrogators gave the lawyer the following instruction: 'You shall not interfere with the interrogation; do not answer any questions posed to the suspect; do not comment on any questions; you shall not be in contact with the suspect during the interrogation; it is prohibited to tape the interrogation; if you do not comply with these rules, we will stop the interrogation and order you to leave.' Such an instruction reduces the lawyer to a silent observer, not unlike a memory-less video-recorder. Although knowing that a lawyer is present may positively affect the suspect and the interrogators, it remains to be seen whether the presence of a lawyer indeed protects the suspect from giving a false confession. ${ }^{23}$

In conclusion, although false confessions are counterintuitive because of their self-inflicting nature, the experimental research suggests that innocent individuals are surprisingly easily seduced to falsely confess a crime. And these scientific data do construe a warning that confession evidence may not be as strong as our intuition dictates.
19. S.M. Kassin, 'On the Psychology of Confessions: Does Innocence Put Innocents at Risk?', 60 American Psychologist 215 (2005).

20. S.R. Gross and B. O'Brien, 'Frequency and Predictors of False Convictions: Why We Know So Little, and New Data on Capital Cases', 5 Journal of Empirical Legal Studies 927 (2005).

21. Kassin (2007).
22. S.M. Kassin, J. Kukucka, V.Z. Lawson \& J. DeCarlo, 'Does Video Recording alter the Behavior of Police during Interrogation? A Mock Crime-and-Investigation Study', 38 Law and Human Behavior 73 (in press).

23. W.J. Verhoeven and L. Stevens, 'The Lawyer in the Dutch Interrogation Room: Influence on Police and Suspect', 9 Journal of Investigative Psychology and Offender Profiling 69 (2012). 
Table 2 Percentages of confessing participants as a function of interrogation tactic.

\begin{tabular}{llll}
\hline & True confession & False confession & Diagnostic value \\
\hline No tactic & 46 & 6 & 7.7 \\
\hline Deal & 72 & 14 & 5.1 \\
\hline Minimisation & 81 & 18 & 4.5 \\
\hline Deal + minimisation & 87 & 43 & 2.0
\end{tabular}


Table 3 Main results of the experiments (in chronological order) on false confessions.

\begin{tabular}{|c|c|c|c|c|c|c|}
\hline Authors & Paradigm & Sample & $\begin{array}{l}\text { Guilty } \\
n\end{array}$ & $\begin{array}{l}\text { True con- } \\
\text { fessions } \\
(\%)\end{array}$ & $\begin{array}{l}\text { Innocent } \\
n\end{array}$ & $\begin{array}{l}\text { False confessions } \\
(\%)\end{array}$ \\
\hline Kassin \& Kiechel (1996) & Computer crash & Students & - & - & 75 & $52(69 \%)$ \\
\hline Forrest et al. (2002) & Computer crash & students & - & - & 56 & $34(61 \%)$ \\
\hline Horselenberg et al. (2003) & Computer crash & Students & - & - & 34 & $27(82 \%)$ \\
\hline Redlich \& Goodman (2003) & Computer crash & $12-26$ year olds & - & - & 96 & $67(70 \%)$ \\
\hline Candel et al. (2005) & Computer crash & $6-9$ year olds & - & - & 50 & $18(36 \%)$ \\
\hline Russano et al. (2005) & Cheating/fraud & Students & 148 & $107(72 \%)$ & 148 & $30(20 \%)$ \\
\hline \multirow[t]{3}{*}{ Horselenberg et al. (2006) } & Computer crash & Students & - & - & 56 & $38(68 \%)$ \\
\hline & Computer crash & Students & - & - & 9 & $1(11 \%)$ \\
\hline & Cheating/fraud & Students & - & - & 12 & $1(8 \%)$ \\
\hline Forrest et al. (2006) & Computer crash & Students & - & - & 98 & $80(82 \%)$ \\
\hline Billings et al. (2007) & Mock crime & $5-9$ year olds & - & - & 99 & $12(12 \%)$ \\
\hline Blair (2007) & Computer crash & Students & - & - & 196 & $54(28 \%)$ \\
\hline Klaver et al. (2008) & Computer crash & Students & - & - & 219 & $88(40 \%)$ \\
\hline \multirow[t]{2}{*}{ Nash \& Wade (2009) } & Virtual theft & Students & - & - & 30 & $30(100 \%)$ \\
\hline & Virtual theft & Students & - & - & 30 & $28(93 \%)$ \\
\hline \multirow[t]{3}{*}{ Perillo \& Kassin (2011) } & Computer crash & Students & - & - & 71 & $43(61 \%)$ \\
\hline & Computer crash & Students & - & - & 38 & $22(60 \%)$ \\
\hline & Computer crash & Students & - & - & 59 & $34(58 \%)$ \\
\hline Narchet et al. (2011) & Cheating/fraud & Students & 90 & $80(89 \%)$ & 90 & $26(29 \%)$ \\
\hline Horgan et al. (2012) & Cheating/fraud & Students & 66 & $59(89 \%)$ & 66 & $21(32 \%)$ \\
\hline Jordan et al. (2012) & Mock crime & Students & 36 & $6(17 \%)$ & 27 & $1(4 \%)$ \\
\hline Total & & & 340 & $252(74 \%)$ & 1559 & $707(45 \%)$ \\
\hline
\end{tabular}

Note. Not all authors mention absolute numbers of participant in the respective conditions; in those instances, a $50-50$ base rate is assumed. 